\title{
PERANCANGAN LOGO DAN IDENTITAS VISUAL UNTUK KOTA BOGOR
}

\section{Logo and Visual Identity Design For Bogor City}

\author{
Brian Alvin Hananto ${ }^{1 *}$ \\ ${ }^{1}$ Program Studi Desain Komunikasi Visual, Universitas Pelita Harapan, Tangerang \\ Diterima: 13 Januari 2019 Tahun / Disetujui: 4 Maret 2019
}

\begin{abstract}
Since 2014 the City of Bogor has made several programmes that are intended to raise its brand. Through multiple events and development, Bogor has able to reach new heights and showcases it's potential to be branded properly. From observations on various sites in Bogor and also reviewing publications and documentation on the designs produced for Bogor; it can be inferred that Bogor's brand touchpoints aren't consistent and do not represent what Bogor's essential identity was. Later on, after a series of studies and interviews, it is concluded that Bogor has a dire need of a brand identity redesign, starting with its visual identity. The need for identity is answered with two alternative logo designs that are shown in this paper. Both designs attempt to show parts of Bogor's identity and heritage through a rationale and a contemporary approach to designing a logo. Though the design project was a simulation for a student's final project, the designs were evaluated and presented to the staffs of the Bogor City government; one design is selected and developed further to visual elements that are implemented on several items and brand touchpoints. In the end, this paper attempts to show a comprehensive design process on designing a visual identity for a city, starting from the research, ideation and also crafting the visuals.
\end{abstract}

Keywords: Logo Design, Visual Identity, City Branding, Bogor

\begin{abstract}
ABSTRAK
Sejak tahun 2014, Kota Bogor telah banyak menjalankan program-program yang ditujukan untuk meningkatkan brandnya. Dengan berbagai acara dan pengembangan infrastruktur, Bogor telah berhasil menunjukkan bahwa dirinya mampu dibranding dengan baik. Dari observasi pada beberapa tempat di Bogor, dan juga meninjau dokumentasi dan publikasi untuk Kota Bogor, dapat disimpulkan bahwa brand touchpoints dari Kota Bogor kurang konsisten dan tidak merepresentasikan esensi dari identitas Kota Bogor. Kemudian, setelah dilakukan studi dan wawancara, maka disimpulkan bahwa Kota Bogor membutuhkan sebuah redesain terhadap brand identitynya, dan hal itu dimulai dari identitas visualnya. Kebutuhan akan identitas visual tersebut direspon dengan dua alternatif desain logo yang ditampilkan dalam tulisan ini. Kedua desain logo tersebut berusaha merepresentasikan nilai-nilai yang berbeda dengan pendekatan yang rasional dan kontemporer dalam mendesain sebuah logo. Walaupun proyek desain ini adalah proyek simulatif untuk keperluan tugas akhir mahasiswa, kedua desain logo tersebut dipresentasikan dan dievaluasi kepada beberapa staf pemerintah Kota Bogor; hasilnya adalah salah satu desain dipilih dan dinyatakan cukup representatif untuk dikembangkan lebih lanjut dan kemudian diimplementasikan kepada beberapa brand touchpoints. Pada akhirnya, tulisan ini mencoba untuk menunjukkan sebuah proses desain yang komprehensif dalam mendesain sebuah identitas visual untuk sebuah kota, dimulai dari riset, penggagasan ide, dan juga pembuatan visual desain.
\end{abstract}

Kata Kunci: Desain Logo, Identitas Visual, Branding Kota, Bogor

\section{PENDAHULUAN}

Bagian ini akan menjelaskan latar belakang mengenai tulisan yang akan dilanjutkan dengan penjelasan sederhana mengenai latar belakang isu atau tema tulisan.

*email: brian.hananto@uph.edu 
Tulisan ini adalah rangkuman dari penelitian dan laporan penelitian yang penulis lakukan bersama dengan mahasiswi bimbingan penulis, Agnezia Margareta.

Penelitian dan perancangan desain yang dimaksud adalah penelitian dalam konteks tugas akhir dalam tingkat sarjana strata satu Pendidikan program studi Desain Komunikasi Visual di Universitas Pelita Harapan, dalam proses penelitian dan perancangan yang dilakukan Agnezia. Sedangkan dalam proses visualisasi dan eksplorasi desain dibantu oleh Drs. Winoto Usman dalam membimbing Agnezia.

\section{Latar Belakang Isu}

Ketika berbicara mengenai sebuah tempat, terdapat hal-hal yang tentu saja terasosiasi akan tempat hal itu. Asosiasiasosiasi positif maupun negatif tentu tidak dapat dihindari dengan identitas dari sebuah tempat, hal itu pasti akan mempengaruhi persepsi orang-orang akan tempat tersebut. Kata 'tempat' dapat disubstitusikan dengan kata 'kota'. Dengan demikian, persepsi atau citra seseorang akan sebuah kota sedikit banyak akan dipengaruhi oleh identitas dari kota itu sendiri.

Menurut Juan Carlos Belloso (Belloso, 2012), terdapat tiga konsep utama yang dapat dibahas mengenai kota, yaitu identitas kota, citra kota dan juga positioning kota. Identitas kota dapat dipahami sebagai realita dari kota itu sendiri. Realita disini berbicara mengenai nilai, karakter bahkan lokasi-lokasi yang menjadi milik dari kota tersebut. Citra kota berbicara mengenai bagaimana kota tersebut dilihat dari orangorang diluar kota tersebut, khususnya orangorang yang menjadi target market dari kota tersebut (kota di sini dipahami sebagai destinasi). Sedangkan pemahaman mengenai positioning kota sendiri merujuk pada apa yang menjadikan kota tersebut unik ketika dibandingkan dengan kota-kota lain. Yang membedakan positioning kota dengan identitas kota adalah adanya pembanding; bisa saja sebuah kota memiliki banyak keunggulan dan kelebihan, namun ketika dibandingkan dengan kota lain sebagai pembanding, ternyata kota tersebut bukan hal yang unik atau spesial.

Ketika berbicara mengenai perbedaan mengenai identitas kota dan citra kota, hal ini menjadi dasar dari adanya program-program branding atau rebranding kota. Selain semata-mata untuk meningkatkan pengunjung, program branding juga sering kali dilakukan untuk menyamakan citra kota tersebut dengan identitas maupun dengan positioning kota.

Program branding, atau peningkatan citra kota ini sendiri pun akan lebih efektif dengan adanya perancangan logo kota. Menurut Octaviyanti Dwi Wahyurini dalam tulisannya, "The Significance of City Logo in City Branding Strategy", citra kota yang dirangkum dalam sebuah logo akan membantu positioning sebuah kota (Wahyurini, 2012). Hal ini dikarenakan karakter atau nilai dari kota tersebut dapat disimbolkan dalam sebuah grafis yang dapat digunakan. Logo kota ini pasti dapat membantu mengubah persepsi orang-orang, namun perancangan logo sendiri perlu melibatkan stakeholder, seperti pemerintahan dan juga penduduk kota, agar dapat mencerminkan identitas kota tersebut dengan tepat (Lau F., 2011).

Dr. Bima Arya Sugianto selaku Walikota Kota Bogor untuk periode 2014 2019 memiliki visi untuk menjadikan Kota Bogor sebagai kota yang nyaman, beriman dan transparan. Visi itu ingin dicapai dengan misi menjadikan Bogor kota yang cerdas dan berwawasan teknologi informasi dan komunikasi; menjadikan Bogor kota yang sehat dan makmur; menjadikan Bogor kota yang berwawasan lingkungan; menjadikan Bogor sebagai kota jasa yang berorientasi pada kepariwisataan dan ekonomi kreatif; mewujudkan pemerintah yang bersih dan transparan; dan mengokohkan pesan moral agama dan kemanusiaan untuk mewujudkan masyarakat madani. Salah satu bentuk konkret dari misi tersebut adalah sebuah 
program branding kota yang direncanakan oleh Ir. Bima Arya, mengungkapkan bahwa Kota Bogor memiliki beberapa karakteristik yang kuat yang membedakan Kota Bogor dengan kota lainnya. Dikatakan pula bahwa Kota Bogor adalah kota pusaka (heritage city), kota hijau (green city) dan juga kota cerdas (smart city). Upaya dari kota bogor untuk menunjukkan karakteristikkarakteristik tersebut sebenarnya sudah dilakukan. Contoh-contoh upaya yang sudah ditunjukkan adalah dengan pembangunan "Teras Sembilan Pintu Dasakerta" sebagai cerminan kota pusaka, penataan taman dan pembangunan jalur pejalan kaki sebagai cerminan kota hijau, serta pengembangan jaringan yang memudahkan akses wisatawan sebagai cerminan dari kota cerdas.

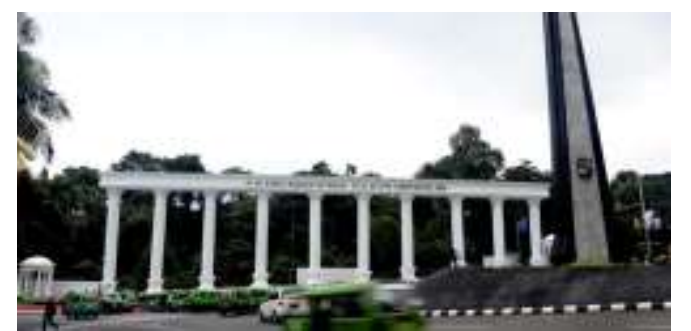

Gambar 1 Teras Sembilan Pintu

Dasakerta

Sumber: jabar.pojoksatu.id

Perubahan-perubahan yang tercipta melalui rangkaian program-program Kota Bogor ini sendiri menjadi suatu hal yang disayangkan ketika tidak dirangkum dalam sebuah identitas visual dan juga logo yang mampu merepresentasikan perubahan-perubahan tersebut. Melihat lebih jauh mengenai media-media komunikasi visual yang dimiliki oleh Kota Bogor dalam periode ini, terdapat banyak inkonsistensi dalam tampilan visual yang digunakan oleh Kota Bogor dalam menjalankan program branding ini.

Kota Bogor sendiri telah memperbaharui tampilan website mereka sejak 26 Maret 2017. Website yang baru itu juga menampilkan sebuah karakteristik visual dan juga logo yang belum pernah ditunjukkan sebelumnya. Namun logo yang ditampilkan dalam website tersebut bukanlah logo dari Kota Bogor, namun logo yang digunakan hanya untuk keperluan website tersebut.

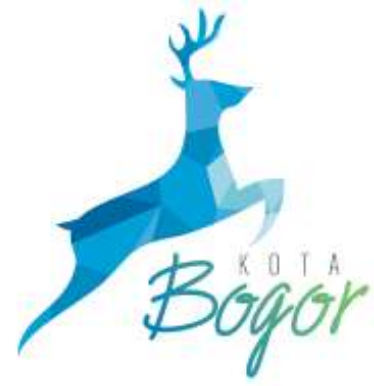

\section{Gambar 2 Logo Website Kota Bogor Sumber: kotabogor.go.id}

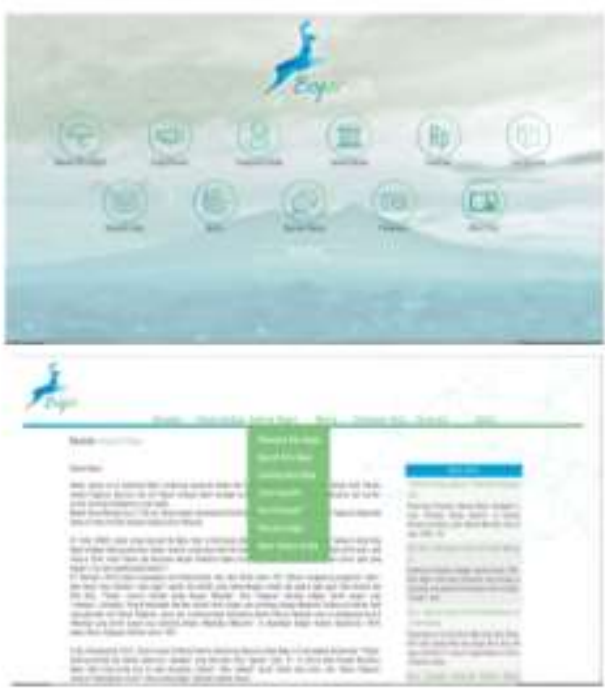

\section{Gambar 3 Tampilan Website \\ Pemerintah Kota Bogor \\ Sumber: kotabogor.go.id}

Berdasarkan pemaparan data-data dan fakta-fakta yang ada, maka perancangan logo dan identitas visual yang telah dilakukan oleh Kota Bogor ini dirasa sebagai kesempatan yang tidak digunakan dengan baik. Sebuah identitas visual yang koheren dan konsisten sedikit banyak tentu dapat membantu program branding kota bogor dengan 'menyamakan' suara dan pesan dari program-program tersebut secara visual. 
Dengan demikian, Desainer mengangkat isu mengenai Kota Bogor sebagai tema dalam tugas akhirnya. Lingkup yang dikerjakan dalam perancangan dan penelitian ini berkisar dari perancangan logo yang mencerminkan nilai-nilai dari Kota Bogor, dan juga sebuah sistem identitas visual yang diaplikasikan dalam rangkaian media dan item-item seperti stationery.

\section{TINJAUAN TEORI}

Bagian ini menjelaskan beberapa konsep dan teori penting mengenai branding dan logo. Pembahasan ini juga menekankan beberapa pertimbangan yang melatari keputusan-keputusan dalam mendesain.

\section{Brand \& Branding}

Brand adalah persepsi yang muncul pada audience mengenai sebuah perusahaan, figur ataupun ide. Dengan demikian, seorang desainer tidak dapat membuat atau merancang sebuah brand, yang dapat dibuat oleh seorang desainer adalah objek-objek yang dapat 'mempengaruhi' persepsi audience (Adams, 2004:18).

Objek atau hal-hal yang dapat dirancang seorang desainer untuk meningkatkan brand adalah brand touchpoints. Brand touchpoints ini sangat luas karena objek apa saja yang membangun persepsi kita terhadap sebuah brand dapat termasuk didalamnya: logo, website, iklan, publikasi, kartu nama, kop surat, spanduk, dll (Wheeler, 2009:3).

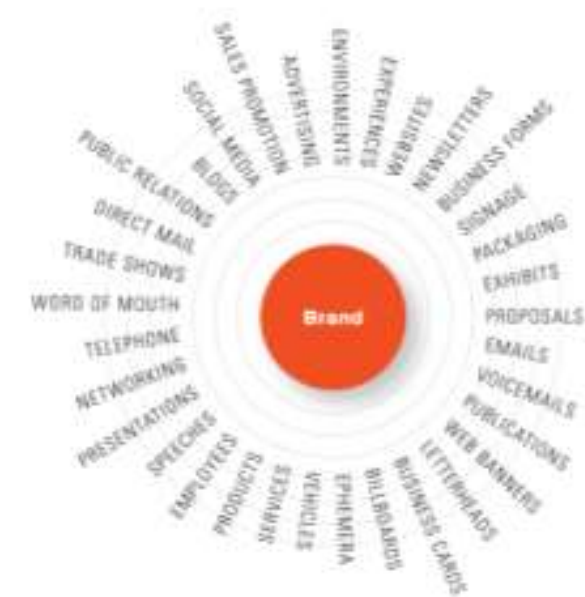

\section{Gambar 4 Brand \& Brand Touchpoints Sumber: Alina Wheeler (2009)}

Melihat banyaknya touchpoints yang ada, maka tidak mustahil jika tidak dikelola dengan baik, terkadang touchpoints tersebut tidak dapat membangun persepsi yang sama. Pengalaman inkonsisten inilah yang terkadang menimbulkan masalah baru yang perlu ditanggulangi. Menjaga konsistensi dari sebuah brand touchpoints inilah yang disebut sebagai menjaga identitas dari sebuah brand, atau brand identity (Wheeler, 2009:4).

Proses membangun kesadaran masyarakat atau audience terhadap sebuah brand adalah kegiatan yang dikenal sebagai branding. Dalam branding, yang dikelola adalah brand touchpoints dan brand identity dari sebuah entitas. Harapannya, dengan secara konsisten dan intensif, branding dapat meningkatkan loyalitas audience atau pelanggan (Wheeler 2009:6).

\section{Logo}

Logo sendiri merupakan salah satu bagian dari brand identity. Wheeler (2009) menggunakan istilah signature untuk mendeskripsikan logo, dan membagi signature atas beberapa bagian kecil yang dapat dilihat pada Gambar 5 (Wheeler, 2009:50). 


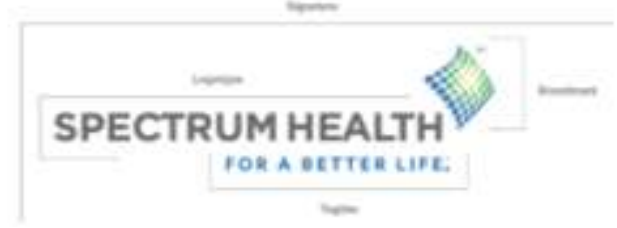

\section{Gambar 5 Bagian dari Sebuah Signature Sumber: Alina Wheeler (2009)}

\section{METODOLOGI PENELITIAN}

Proses perancangan dilakukan dalam kurun waktu kurang lebih satu tahun. Dalam enam bulan pertama, perancangan berfokus pada proses pengumpulan data dan juga pengolahan data-data yang telah dikumpulkan. Pada enam bulan berikutnya, perancangan bergeser fokusnya pada pengembangan dan proses-proses yang berkaitan dengan visual. Proses perancangan dapat dilihat dengan lebih detil pada bagan yang tertera pada Gambar 6.

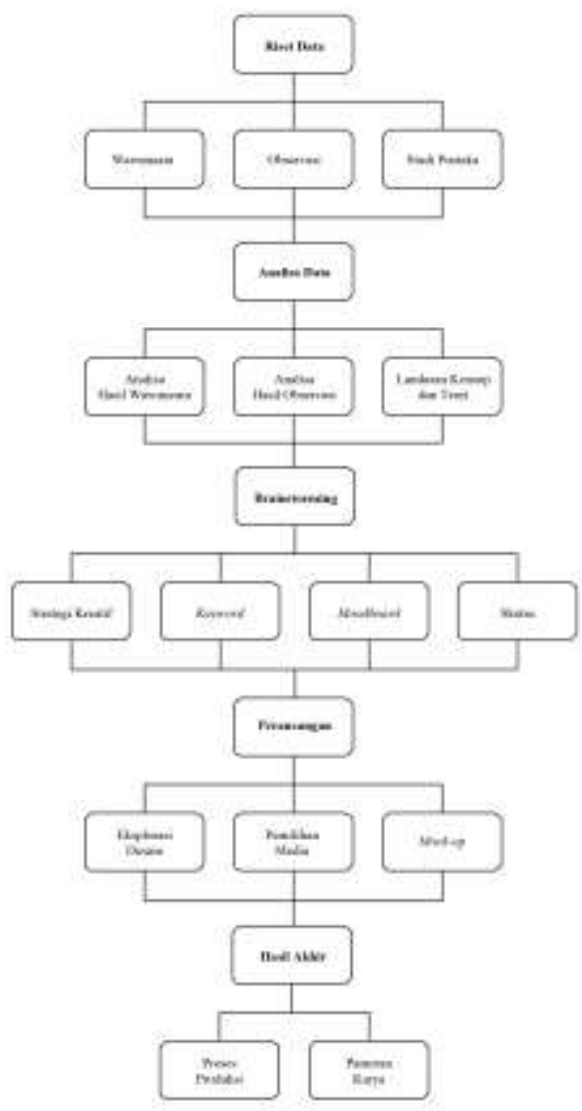

Gambar 6 Skema Perancangan

\section{Sumber: Dokumentasi Penulis (2019)}

Tahapan dan metode yang dilakukan dalam penelitian ini akan dibahas lebih lanjut pada pemaparan-pemaparan selanjutnya

\section{Riset Data}

Fase riset data dilakukan dengan tiga cara, melalui wawancara, observasi dan juga studi pustaka. Studi pustaka dilakukan terhadap pustaka-pustaka yang sifatnya online maupun offline; observasi dilakukan dengan cara mengunjungi Kota Bogor dan melihat secara langsung beberapa situs di Kota Bogor; wawancara dilakukan di Kantor Dinas Kebudayaan Pariwisata dan Ekonomi Kreatif (Disbudparekraf) Kota Bogor untuk mencari data-data dan opini ahli yang tidak ditemukan dalam pustaka.

\section{Analisa Data}

Fase analisa data dilakukan dengan cara mengolah data-data mentah yang didapat dan membandingkan data-data tersebut, seperti membandingkan apa yang diperoleh dari studi pustaka dengan hasil wawancara, membandingkan hasil wawancara dengan observasi, dan seterusnya. Hasil Analisa data digunakan untuk mencari landasan terhadap pengembangan desain logo dan identitas visual Kota Bogor yang akan dirancang.

\section{Brainstorming}

Tahap ketiga adalah fase brainstorming dimana tahapan ini mulai bergelut dengan visual. Berdasarkan data yang telah dianalisa, desainer mengembangkan landasan konsep dan ide untuk merancang. Strategi-strategi yang dihasilkan kemudian disimpulkan dalam sebuah keyword visual, yang dikembangkan menjadi sebuah moodboard dan sketsasketsa awal desain.

\section{Perancangan}

Tahap perancangan adalah fase keempat yang merupakan bentuk perancangan lebih mendetil dan terfokus kepada solusi visual yang telah ditentukan. Pada tahapan ini, desainer menentukan 
alternatif desain $\log 0$ dan kemudian mengembangkannya menjadi desain yang komprehensif. Logo tersebut kemudian dikembangkan juga menjadi identitas visual yang dapat digunakan pada media dan item yang diperlukan.

\section{Hasil Akhir}

Hasil akhir dalam proses perancangan ini adalah memproduksi desain-desain yang telah dibuat. Desain diproduksi untuk kepentingan pameran dan juga keperluan proyek akhir Desainer.

\section{PROSES PERANCANGAN}

Bagian ini menjelaskan dengan sederhana mengenai proses perancangan yang dilakukan, mulai dari mengumpulkan data, membuat strategi visual sampai dalam proses perancangan dan pembuatan visual.

\section{Pengumpulan \& Analisa Data}

Data yang dikumpulkan adalah data yang didapat dari studi pustaka, observasi dan juga wawancara yang Desainer lakukan. Berikut adalah beberapa data yang krusial dan berhubungan erat dengan perancangan yang dilakukan.

\section{Program Branding Kota Bogor}

Program branding dari Kota Bogor dicetuskan oleh Ir. Bima Arya. Mengenai hal tersebut, beliau menjelaskan dalam artikel "Perbaiki Infrastruktur Dulu, Baru Perkuat Branding Kota Bogor" [10], pada tahun pertama pemerintahannya, Ir. Bima Arya akan menata Kota Bogor terlebih dahulu, kemudian tahun kedua akan melakukan persiapan terhadap program branding tersebut, dan tahun ketiga baru dengan 'agresif' akan menjalankan program branding tersebut.

Dalam tulisan lain di situs Kota Bogor, terdapat pemaparan Ir. Bima Arya mengenai semboyan Kota Bogor yang dipahat di Tepas Salapan Lawang, "Dinu Kiwari Ngancik $\mathrm{Nu}$ Bihari, Seja Ayeuna Sampeureun Jaga". Ir Bima Arya menjelaskan lebih lanjut bahwa prinsip pemerintahannya adalah "Preserving The
Heritage, Serving The People, Facing The Future" yang menurutnya melandasi anganangan supaya Bogor menjadi Kota pusaka, kota hijau, dan kota cerdas.

\section{Visual Audit}

Visual audit berbicara mengenai observasi dan juga penilaian kepada komponen-komponen visual relevan yang ditemukan selama proses penelitian. Visual yang dibahas dalam tahapan ini meliputi lambang kota, stationery, dan juga beberapa media cetak lain dari Kota Bogor.

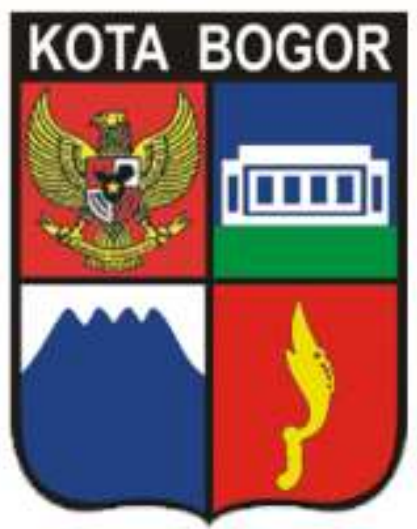

\section{Gambar 7 Lambang Kota Bogor Sumber: kotabogor.go.id}

Pada lambang kota bogor ini terdapat empat lambang, yaitu:

1. Sisi kiri atas menggunakan lambang Garuda Indonesia selaku lambang negara.

2. Sisi kanan atas menggunakan lambang Istana Bogor.

3. Sisi kiri bawah menggunakan lambang Gunung Salak.

4. Sisi kanan bawah menggunakan lambang senjata kurang, yang merupakan pusaka peninggalan kerajaan Pajajaran.

Pemerintahan Kota Bogor sendiri memiliki stationery yang berbeda berdasarkan tiap Sistem Kerja Perangkat Daerah (SKPD). Karena didesain kurang baik, terdapat inkonsistensi yang ditemukan pada beberapa stationery tersebut, contohnya dapat dilihat pada kop surat yang dapat dilihat pada Gambar 8 berikut. 


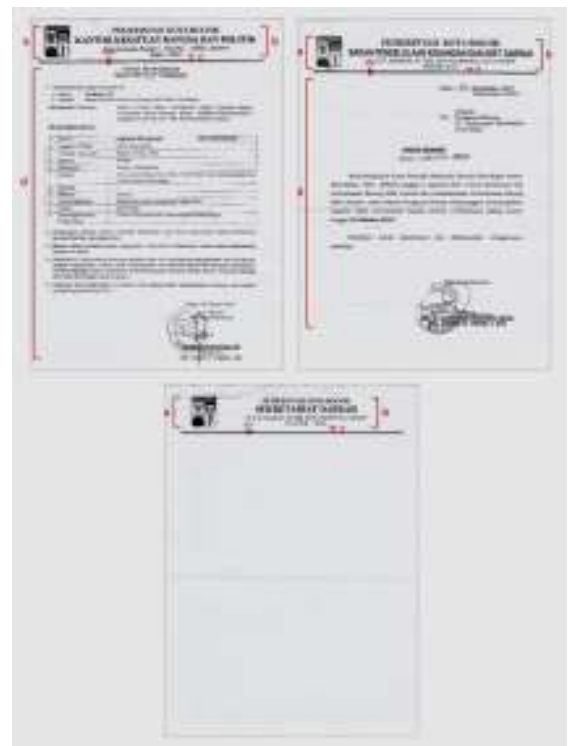

\section{Gambar 8 Perbandingan Tiga Kop Surat SKPD Kota Bogor Sumber: Kantor Humas Kota Bogor}

Pada lambang kota bogor ini terdapat empat lambang, yaitu:

a. Lambang Kota Bogor: Terdapat perbedaan ikon dan bentuk pada lambang Kota Bogor, selain itu penggunaan typeface untuk tulisan "KOTA BOGOR" juga berbeda pada tiap kop surat.

b. Keterangan SKPD: pengaturan tipografis untuk keterangan SKPD tidak konsisten, baik dari pemilihan typeface, ukuran huruf dan juga jarak-jarak teks.

c. Jarak antara kop surat dan elemen garis pemisah tidak konsisten.

d. Penggunaan typeface untuk isi teks tidak konsisten, baik dari ukuran, pengaturan jarak antar baris, dan juga alignment teks.

Inkonsistensi juga ditemukan bukan hanya pada kop surat, namun juga pada kartu pengenal karyawan dari staff kantor pemerintahan Kota Bogor.
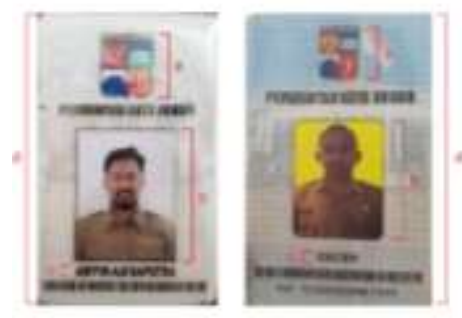

\section{Gambar 9 Perbedaan Dua Kartu Tanda Pengenal Karyawan Kantor Pemerintahan Kota Bogor Sumber: Dokumentasi Pribadi (2019)}

Dapat dilihat bahwa terdapat beberapa perbedaan, baik dari perbedaan yang subtil maupun yang terlihat jelas, seperti:

a. Lambang Kota Bogor yang digunakan sedikit berbeda, baik dari Lambang Garuda Indonesia dan juga proporsi lambang Kota Bogor secara keseluruhan.

b. Penggunaan warna latar yang berbeda untuk foto profil.

c. Penggunaan jenis typeface yang berbeda antara kedua desain kartu. Selain itu satu kartu mencantumkan NIP dari karyawan tersebut, sedangkan satu lagi tidak mencantumkan NIP.

d. Penggunaan latar kartu yang berbeda antara kedua desain kartu.

Pemerintah Kota Bogor sendiri juga sempat menerbitkan sebuah peta Kota Bogor yang berisikan informasi tempat wisata yang ada dan dapat dikunjungi di Kota Bogor.
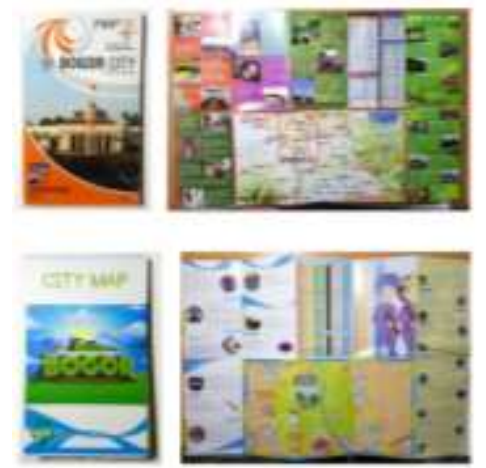

\section{Gambar 10 Tampilan Bogor City Map 2015 (atas) \& 2016 (bawah) \\ Sumber: Kantor Disbudparekraf Kota Bogor}

Melihat banyaknya item-item yang dihasilkan, sangat disayangkan bahwa desain-desain yang dibuat dan dipublikasikan banyak yang tidak konsisten secara visual. Hal ini mendasari juga adanya suatu perancangan identitas visual yang aplikatif dan fleksibel untuk segala keperluan Kantor Disbudparekraf Kota Bogor. 


\section{Kujang}

Berdasarkan wawancara yang dilakukan Desainer dengan Guru Teupa (pembuat kujang) di Bandung, Wahyu Affandi Suradinata pada 9 Oktober 2017, didapat beberapa informasi-informasi mengenai Kujang itu sendiri. Kujang adalah Warisan Budaya Tak Benda dan merupakan sebuah bentuk Hak Kekayaan Intelektual. Kujang sendiri merupakan suatu bagian identitas masyarakat Jawa Barat, khususnya masyarakat Sunda.

Terdapat beberapa jenis Kujang yang dibedakan berdasarkan fungsi:

1. Kujang Pusaka, adalah sebuah kujang yang dibuat dengan dekorasi dengan menutup matanya dengan logam mulia, seperti emas atau perak. Kujang pusaka dipercaya memuat ilmu-ilmu gaib atau magis yang digunakan sebagai pegangan pribadi sang pemilik.

2. Kujang Pakarang, adalah sebuah kujang yang digunakan sebagai senjata. Kujang Pakarang sering kali dibubuhi oleh racun dan diberikan bisa ular.

3. Kujang Pangarak, adalah sebuah kujang yang digunakan sebagai perlengkapan untuk upacara adat, upacara keagamaan, maupun upacara kenegaraan.

4. Kujang Pamangkas, sebuah kujang yang merupakan alat untuk memangkas semak belukar pada lahan.

Sedangkan menurut Pantun Bogor, terdapat enam jenis kujang berdasarkan bentuknya, yakni:

1. Kujang Ciung yang memiliki ujung menyerupai kepala burung ciung.

2. Kujang Kuntul yang memiliki ujung menyerupai kepala burung kuntul.

3. Kujang Jago yang memiliki ujung menyerupai kepala ayam jago.

4. Kujang Naga yang memiliki ujung menyerupai kepala naga.

5. Kujang Bangkong yang memiliki ujung menyerupai kepala bangkong.

6. Kujang Badak yang memiliki ujung menyerupai kepala badak.
Berdasarkan Pantun Bogor, Kujang menjadi sebuah simbol yang digunakan untuk menunjukan simbol status berdasarkan kujangnya. Jenis-jenis simbol kujang dilihat dari status orang yang memilikinya adalah:

1. Kujang Ciung mata sembilan yang dimiliki oleh para Raja dan Brahmesta.

2. Kujang Ciung mata tujuh yang dimiliki oleh para Prabu Anom (Putra Mahkota) dan Para Pandita.

3. Kujang Ciung mata lima yang dipegang oleh para Bopati (Raja bawahan atau adipati), Geurang Seurat (wakil bupati), dan Para Mayang (wanita bersuami).

4. Kujang Ciung Mata tiga yang dipegang Para Puun (ketua adat) dan para Kania (Gadis Pajajaran).

5. Kujang Kuntul yang dipegang para Patih (Perdana Menteri) dan Para Mantri.

6. Kujang Jago yang dipegang para Balapati (Panglima Perang) dan para Lulugu (Komandan Pasukan).

7. Kujang Naga yang dipegang para Kanduru (utusan raja) dan Para Jaro (Tetua Masyarakat).

8. Kujang Badak yang dipegang para Sarawarsa (Prajurit)

9. Kujang Bangkong yang dipegang Para Guru (Ahli atau Tukang).

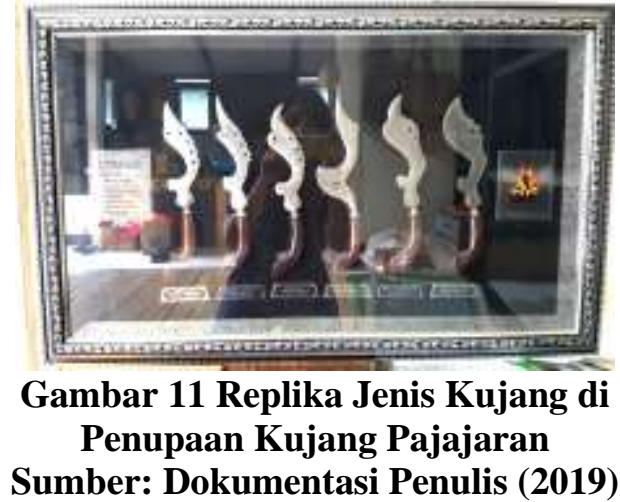

\section{Strategi Visual}

Dalam proses perancangan, terdapat empat tahapan yang dilakukan guna mendapatkan konsep untuk perancangan yang dilakukan. Tahap pertama adalah 
membuat peta pemikiran atau mind map. Dari pembuatan peta pemikiran itu, Desainer mampu mendapatkan beberapa kata kunci yang merupakan karakteristik dari Kota Bogor. Kedua kata kunci tersebut adalah progresif dan bersahabat (friendly). Setelah mendapatkan kata kunci, desainer kemudian mengembangkan desain-desain dalam bentuk sketsa, yang kemudian dibuat komprehensif secara digital.

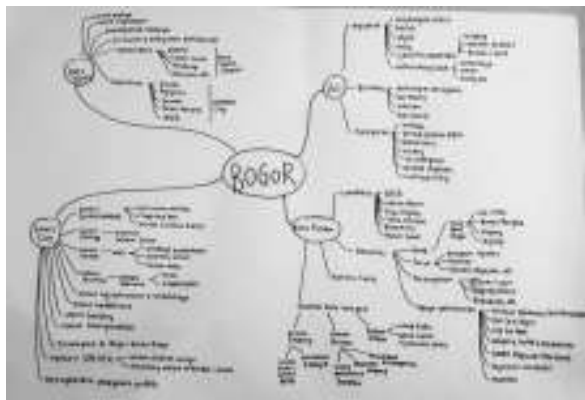

\section{Gambar 12 Peta Pemikiran Untuk Perancangan}

Sumber: Dokumentasi Penulis (2019)

\section{HASIL DAN PEMBAHASAN}

\section{Alternatif Desain Pertama}

Mengambil konsep desain dari Kujang Ciung Mata Sembilan yang merupakan pusaka peninggalan dari Kerajaan Sunda Galuh. Selain menjadi simbol masyarakat Sunda, Kujang juga telah diakui sebagai simbol Kota Bogor dengan dibangunnya Tugu Kujang. Seperti yang dibahas sebelumnya, Kujang Ciung Mata Sembilan merupakan kujang yang dipegang atau dibawa oleh para Prabu (atau para raja). Sehingga kujang ini merupakan kujang dengan tingkatan tertinggi.

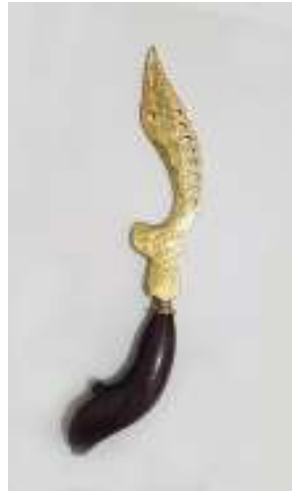

\section{Gambar 13 Kujang Ciung Mata Sembilan}

Sumber: Dokumentasi Penulis (2019)

Desainer membuat sketsa bentuk Kujang dalam berbagai pendekatan. Salah satu bentuk Kujang yang memiliki bentuk melengkung-lengkung itu dipetakan dalam grid yang dibangun dari berbagai ukuran lingkaran. Perbandingan ukuran dari lingkaran-lingkaran tersebut memiliki relasi proporsi golden section, sehingga pendekatan desain dengan bantuan grid ini menghasilkan bentuk yang cukup seimbang dan proporsional.

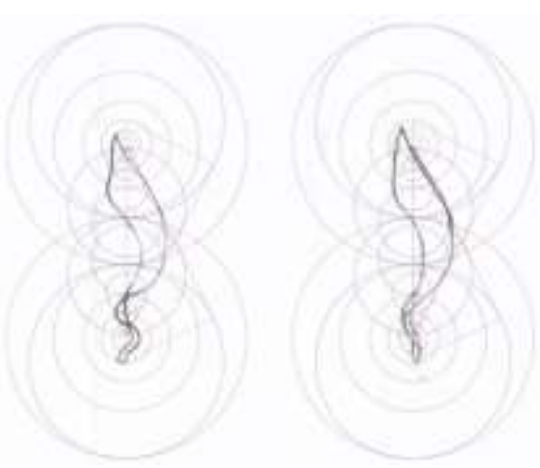

\section{Gambar 14 Sketsa Logogram dengan Pendekatan Kujang \\ Sumber: Dokumentasi Penulis (2019)}

Setelah mendapatkan bentuk dasar, desainer kemudian membuat desain logogram secara digital dan menambahkan detil-detil yang sebelumnya tidak disketsa, seperti bentuk liukan gagang kujang, mata dari kujang, serta bentuk kepala kujang Ciung. Setelah mendapatkan bentuk logogram yang kurang 
lebih diinginkan, desainer kemudian memberikan warna yang sesuai dengan karakteristik progresif dan juga bersahabat.

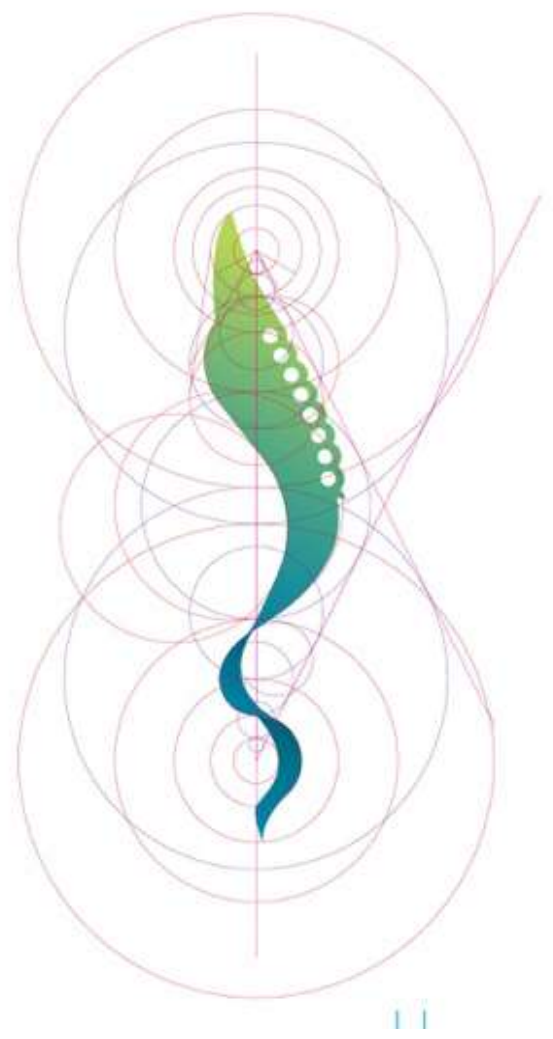

\section{Gambar 15 Desain Secara digital dan Penyempurnaan Optikal Logogram Kujang}

Sumber: Dokumentasi Penulis (2019)

Setelah mendapatkan bentuk logogram yang diinginkan, desainer kemudian menambahkan logotype yang digunakan untuk menyeimbangkan bentuk logogram dan memberikan fondasi serta struktur terhadap logo secara keseluruhan.

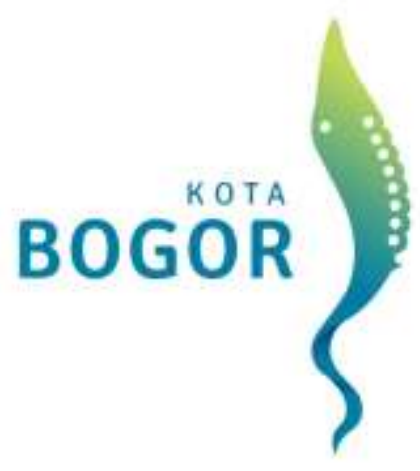

\section{Gambar 16 Alternatif Desain Pertama Sumber: Dokumentasi Penulis (2019)}

\section{Alternatif Desain Kedua}

Konsep kedua yang digunakan oleh desainer dalam membuat logo adalah tanduk axis deer, sebuah spesies rusa yang banyak ditemukan di halaman Istana Bogor. Rusa yang didatangkan pada tahun 1808 oleh Gubernur Jendral Belanda memiliki tujuan untuk menghiasi halaman Istana Bogor. Karena lokasi istana yang ada di tengah Kota Bogor, maka rusa ini sering dijumpai oleh orang-orang, baik masyarakat lokal maupun turis. Hal ini menjadi karakteristik dan identitas tersendiri dari Kota Bogor, dimana fauna yang bersahabat ini merupakan salah satu binatang khas dari Kota Bogor dibandingkan daerah-daerah sekitarnya.

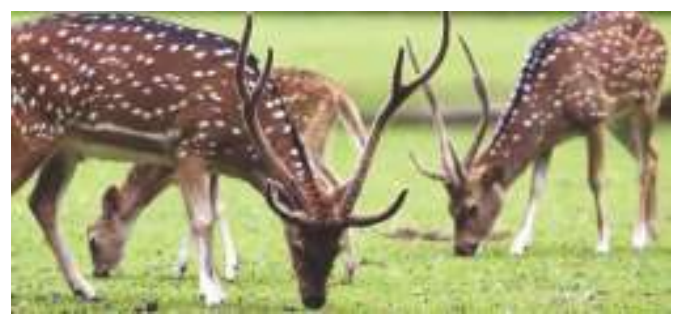

\section{Gambar 17 Axis Deer di Istana Bogor Sumber: infobogor.com}

Kekhasan bentuk tanduk rusa tersebut adalah adanya tiga cabang, sebuah karakteristik yang tidak semua spesies rusa miliki. Hal ini melatari pengembangan bentuk logogram dari tanduk axis deer. Pengembangan logogram ini dilakukan pada sebuah grid isometrik secara manual, yang 
kemudian dibuat versi digital dengan komputer secara dengan penyesuaian secara optikal.
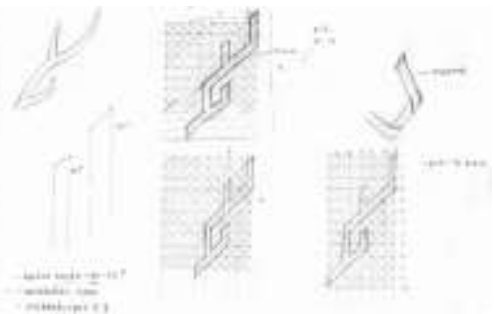

Gambar 18 Sketsa Logogram dengan Pendekatan Tanduk Axis Deer Sumber: Dokumentasi Penulis (2019)

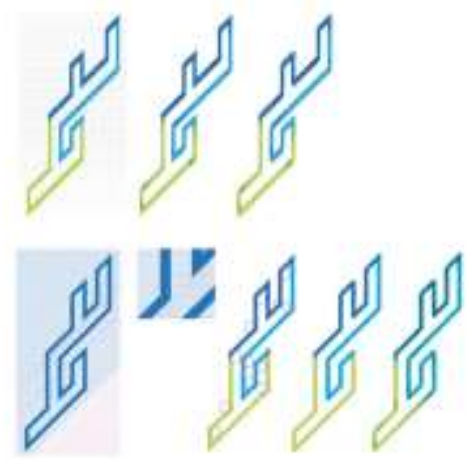

Gambar 19 Desain Secara digital dan Penyempurnaan Optikal Logogram Tanduk Axis Deer

Sumber: Dokumentasi Penulis (2019)

Setelah merapikan bentuk logogram, desainer kemudian melanjutkan proses desain logo dengan menggabungkannya dengan logotype yang telah dipersiapkan. Hasilnya adalah desain yang merupakan pengembangan lebih lanjut dari desain yang sebelumnya telah dimiliki oleh Pemerintah Kota Bogor dan ditemukan dalam website resminya. Desain logo ini secara umum menunjukkan kesan progresifnya dengan bentuk logogram serta konfigurasi dari logotype dan logogramnya; sedangkan kesan bersahabatnya ditunjukkan dengan menggunakan sosok fauna yang khas dari Kota Bogor serta terkenal ramah dan bersahabat.

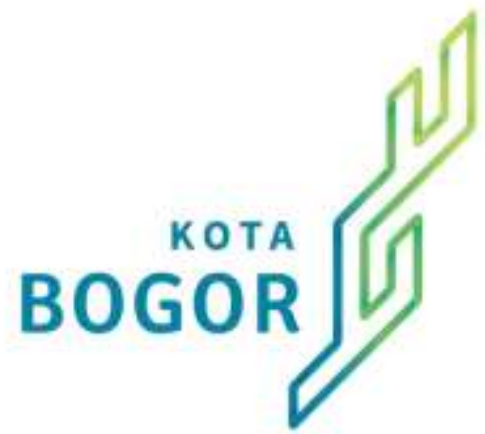

Gambar 20 Alternatif Desain Kedua Sumber: Dokumentasi Penulis (2019)

\section{Desain Akhir}

Kedua logo yang telah dikembangkan kemudian ditunjukkan kepada para staff Kantor Hubungan Masyarakat Bogor. Para staff tersebut menjadi responden yang diminta pendapatnya dan menjawab: dari kedua alternatif logo, manakah yang dinilai lebih merepresentasikan Kota Bogor. Dari 32 responden yang diminta pendapatnya, 25 orang memilih alternatif logo pertama. Alasan kuat yang diungkapkan adalah objek kujang dinilai sebagai sesuatu yang memiliki latar belakang historis. Selain itu, pada lambang Kota Bogor sendiripun terdapat Lambang Kujang.

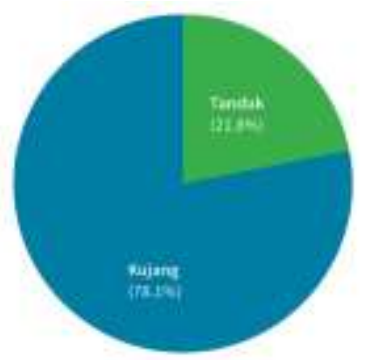

\section{Gambar 21 Perbandingan Hasil Survey Sumber: Dokumentasi Penulis (2019)}

Setelah mendapatkan alternatif logo, desainer kemudian lanjut merancang elemen grafis yang kemudian diterapkan pada stationery dan beberapa item yang telah ditentukan berdasarkan wawancara dan 
observasi. Dalam perancangan ini, desainer merancang untuk enam SKPD dan membuat desain-desain yang mengakomodir keenam SKPD. Variasi yang dihasilkan bukan semata-mata untuk kepentingan agar menarik dan estetis, namun untuk kepentingan informatif juga. Karena setiap SKPD akan mendapatkan variannya sendiri agar dapat dikenali stationery atau item memiliki elemen grafis yang berbeda-beda. Walaupun berbeda-beda, namun setiap elemen grafis tersebut memiliki konsistensi visual yang membantu menjaga sistem identitas visual yang dirancang.

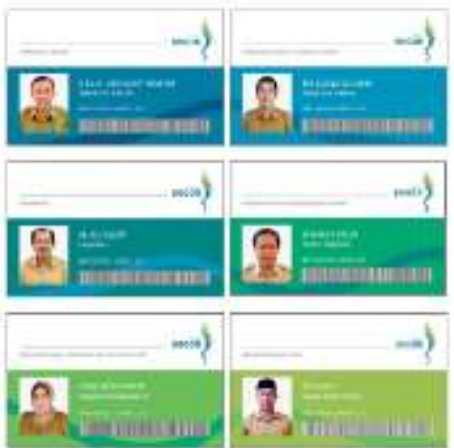

\section{Gambar 22 Enam Varian Kartu Pengenal}

Sumber: Dokumentasi Penulis (2019)

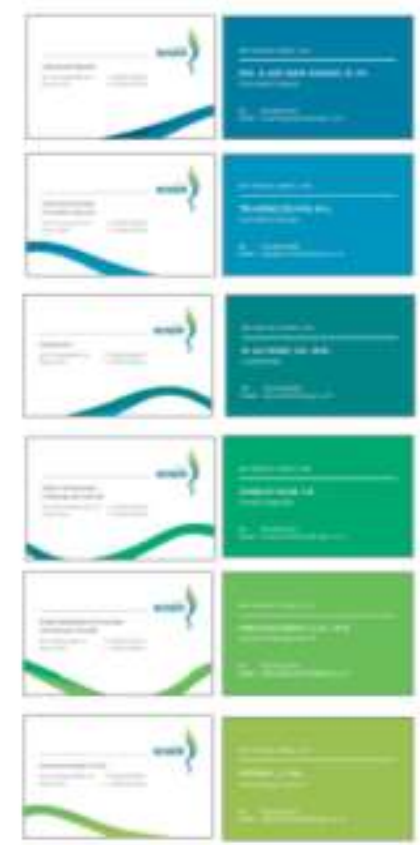

Gambar 23 Enam Varian Kartu Nama
Sumber: Dokumentasi Penulis (2019)

Segala item yang dihasilkan juga ditampilkan pada pameran karya tugas akhir DKV UPH yang diselenggarakan pada bulan Desember 2017 di Plaza Indonesia.

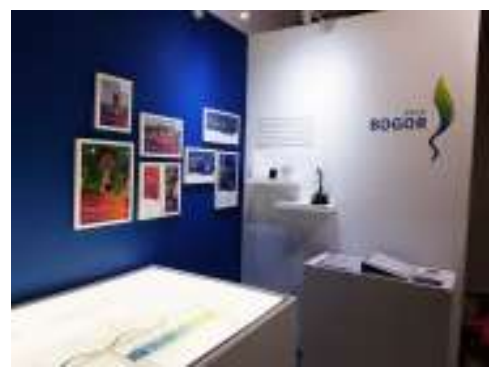

Gambar 24 Booth Pameran Desainer Sumber: Dokumentasi Penulis (2019)

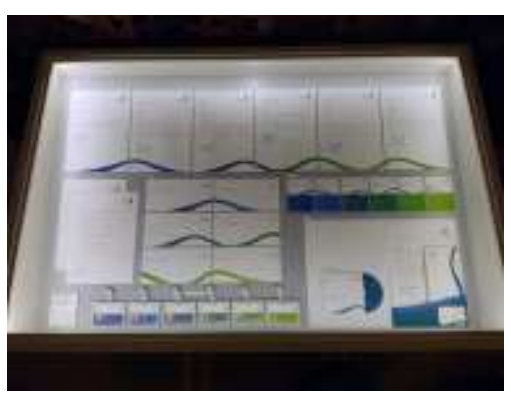

Gambar 25 Stationery yang dirancang oleh Desainer

Sumber: Dokumentasi Penulis (2019)

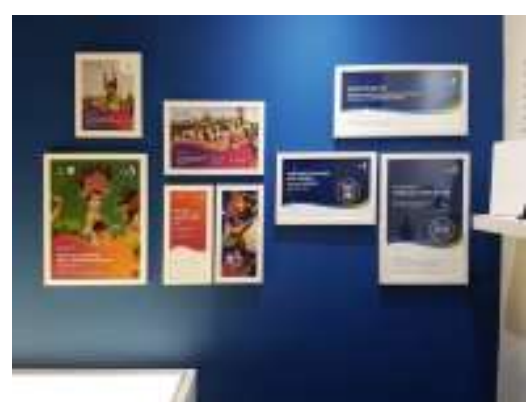

Gambar 26 Media Promosi untuk Kota Bogor yang dihasilkan

Sumber: Dokumentasi Penulis (2019)

\section{SIMPULAN}

Berdasarkan pemaparan-pemaparan yang telah disampaikan, terdapat beberapa 
hal yang dapat sampaikan terkait penelitian dan perancangan ini:

1. Program branding perlu melihat dan mengelola dengan konsisten brand identity dalam brand touchpoints yang ada. Menggalakkan sebuah program branding juga perlu memperhatikan hal-hal yang bersifat mendetil atau mikro, agar koheren dengan perencanaan dan gambaran makro dari program tersebut.

2. Salah satu komponen dalam brand identity yang perlu diperhatikan adalah identitas visual, atau visual identity. Hal ini perlu menjadi perhatian khusus karena aspekaspek brand touchpoints mayoritas berinteraksi secara visual dengan audience. Dengan demikian memiliki karakteristik atau identitas yang seragam untuk visual-visual brand touchpoints ini menjadi suatu hal yang signifikan dewasa ini.

3. Logo atau signature merupakan komponen dalam identitas visual yang sering dilihat oleh audience. Oleh karena itu, ada baiknya proses perancangan sebuah identitas visual dimulai dari mendesain logo atau elemen-elemen yang digunakan dalam logo, seperti warna, elemen huruf dan juga elemen bentuk.

4. Setelah signature dibentuk, barulah pengembangan identitas visual kepada item atau brand touchpoints dapat dilakukan. Dengan terus menarik kembali hasil desain kepada signature, maka rancangan identitas visual touchpoints dapat merefleksikan signature.

5. Dalam perancangan sebuah signature, desainer perlu memperhatikan brand touchpoints yang akan digunakan dalam program branding ini. Dengan demikian, desainer dapat memiliki gambaran yang lebih utuh mengenai apa yang perlu didesain, dan sejauh mana desainer perlu mendesain.

\section{ACKNOWLEDGEMENTS}

Penulis ingin menggunakan ruang ini untuk menyampaikan apresiasinya terhadap Agnezia Margareta \& Drs. Winoto Usman atas bantuan dan kolaborasi yang diberikan selama proses perancangan dan penelitian ini.

\section{DAFTAR PUSTAKA}

Adams, Sean \& Noreen Morioka. Logo Design Workbook: a hands-on guide to creating logos. Massachusetts: Rockport, 2004.

Belloso, Juan Carlos. 2012. Building a Strong City Identity. https://www.globalrealestateexperts .com/2012/10/building-a-strongcity-identity/ (diakses pada 15 Februari 2017)

\section{Dinu Kiwari Ngancik Nu Bihari, Seja} Ayeuna Sampeureun Jaga. Accessed on 2018 September 30. Available from: https://kotabogor.go.id/index.php/s how_post/detail/5322/dinu-kiwaringancik-nu-bihari-seja-ayeunasampeureun-jaga

Lambang Kota Bogor. Accessed on 2018 Oktober 1. Available from: https://kotabogor.go.id/index.php/p age/detail/8/lambang-kota-bogor

Lau F., Leung A. 2011. Chongqingg's City Branding. In: Dinnie K. (eds) City Branding. London: Palgrave Macmillan, 2011.

2016. Perbaiki Infrastruktur Dulu, Baru Perkuat Branding Kota Bogor. Accessed on 2018 September 30. Available from: 
http://satpolpp.kotabogor.go.id/inde x.php/show_post/detail/4994/perbai ki-infrastruktur-dulu-baru-perkuatbranding-kotabogor\#.W7DVB2gzYfQ

Visi Misi. Accessed on 2018 September 30. Available from: https://kotabogor.go.id/index.php/p age/detail/416/visi-misi

Wahyurini, Octaviyanti Dwi. The

Significance of City Logo in City

Branding Strategy. Recent

Researches in Engineering Mechanics, Urban \& Naval

Transporation and Tourism.

Cambridge: WSEAS Press, 2012.

Wheeler, Alina. Designing Brand Identity: an essential guide for the entire branding team. $3^{\text {rd }}$ ed. New Jersey: John Wiley \& Sons. 2009. 